\title{
Pola Penyakit Dan Terapi Dengan Pendekatan Empirik Simptomatik Di Desa Gunung Sari
}

\author{
I Gede Yasa Asmara*, Basuki Rahmat \\ Bagian Ilmu Penyakit Dalam, Fakultas Kedokteran, Universitas Mataram, Indonesia
}

\author{
Article history \\ Received: 10-08-2021 \\ Revised: 11-11-2021 \\ Accepted: 28-11-2021 \\ *Corresponding Author: \\ I Gede Yasa Asmara, \\ Bagian Ilmu Penyakit Dalam, \\ Fakultas Kedokteran, \\ Universitas Mataram, Mataram, \\ Indonesia; \\ Email:yasa.asmara@unram.ac.id
}

\begin{abstract}
The recent global economic crisis has resulted in more expensive health care in which, poor families might not get access to proper health care. Furthermore, global warming and pollution could influence change of disease patterns in the world, includes the tropical island of Lombok. For those two factors, it is interesting to know the disease pattern among poor people and also to give positive contribution for free medical care and treatment to them. A survey of disease patterns and free medical care had been done in Gunung Sari village in August 2015. Patient histories were taken using fundamental four and basic seven techniques whereas physical examinations were done by two registered general practitioners. Soon after working diagnosis is confirmed, empiric antibiotic treatment and symptomatic drugs are prescribed to the patients. As a result, 54\% of 136 patients are male and 51,4\% of them aged from 16 to 59 years old. Upper respiratory tract infections, diarrhea, and skin problems were the three common diseases. As for the empiric antibiotic treatment, Amoxycillin is the common agent used (34\%). Moreover, antipyretic and anti-diarrhoea serve as the common symptomatic treatment used $(21,3 \%)$. In a summary, the disease pattern and type of treatment given to poor people in Gunung Sari village were the same as that in other areas.
\end{abstract}

Keywords: disease; pattern; empiric; symptomatic; therapy

Abtrak: Krisis global saat ini menyebabkan biaya kesehatan begitu mahal sehingga menyulitkan masyarat kurang mampu untuk mendapatkan akses pelayanan kesehatan yang memadai. Selain itu, pemanasan global dan polusi mempengaruhi perubahan pola penyakit di dunia termasuk daerah tropis seperti Pulau Lombok. Karena dua faktor tersebut diatas melatarbelakangi keinginan untuk mengeksplorasi pola penyakit pada masyarakat kurang mampu sekaligus memberikan kotribusi positif berupa pelayanan kesehatan gratis untuk meringankan beban kesehatan mereka. Survei pola penyakit dilakukan di Desa Gunung Sari pada bulan Agustus 2015. Metode anamnesis dengan metode empat dasar dan tujuh fundamental serta pemeriksaan fisik dilakukan oleh dua orang dokter. Diagnosis kerja ditegakkan dan terapi dengan pendekatan empirik simptomatik diberikan kepada masyarakat yang datang. Hasilnya, terdapat 136 pasien dengan 54\% laki-laki dan 51,4\% berumur 16-59 tahun. ISPA, diare dan penyakit kulit merupakan tiga penyakit tersering yang diderita oleh masyarakat kurang mampu di Desa Gunung Sari. Berdasarkan terapi yang diberikan, Amoksisilin merupakan antibiotika empirik yang paling banyak diberikan (34\%) sedangkan antipiretik dan antidiare merupakan terapi simptomatis tersering $(21,3 \%)$. Kesimpulannya, pola penyakit masyarakat kurang mampu dan terapi yang diberikan di Desa Gunung Sari sama dengan daerah lain.

Kata Kunci: pola; penyakit; empiric; simptomatik, terapi 


\section{PENDAHULUAN}

Perkembangan jaman dan krisis global menyebabkan biaya kesehatan menjadi relatif mahal dan tidak terjangkau bagi masyarakat, terutama yang kurang mampu (Watkins, 2018). Dari data yang diperoleh dari Kepala Desa Gunung Sari, disebutkan bahwa sekitar 60\% masyarakat di Desa Gunung Sari memiliki tingkat ekonomi kurang mampu, dan sebagian besar hanya memanfaatkan Kartu Indonesia Sehat atau Badan Pengelola Jaminan Kesehatan (BJPS) untuk berobat ke puskesmas. Peran dosen dalam pengabdian kepada masyarakat dan tenaga kesehatan dalam pelayanan kesehatan diperlukan untuk mengatasi masalah ini. Oleh karena itu diperlukan tindakan nyata untuk mengurangi beban hidup mereka.

Pemanasan global dan polusi juga mempengaruhi perubahan pola penyakit di masyarakat (Santos-Guzman et al., 2021). Disamping itu, sanitasi yang buruk merupakan faktor risiko yang mendukung terjadinya banyak kasus penyakit yang sering diderita oleh masyarakat di Kabupaten Lombok Barat (Riskesdas NTB, 2018). Kunjungan masyarakat ke puskesmas Gunung Sari dengan penyakit infeksi saluran pernafasan akut (ISPA), penyakit kulit, diare dan malnutrisi mencapai $70 \%$ per hari (Dinas Kesehatan Lombok Barat, 2013). Pola penyakit akan mempengaruhi jenis dan jumlah obat yang diberikan. Pemberian obat yang rasional penting bagi kesembuhan pasien (Prasetio et al., 2020). Pola penyakit dan pemberian terapi empirik akan sangat berguna dalam pelayanan kesehatan, karena akan menghindari terjadinya polifarmasi terutama pada populasi usia lanjut yang memang sering berkunjung ke puskesmas atau mencari pengobatan gratis (Abdulah et al., 2018; Jiwantoro, 2019).

Survei pola penyakit dan pelayanan kesehatan gratis kepada masyarakat kurang mampu di sekitar Desa Gunung Sari Kabupaten Lombok Barat dilakukan bertepatan dengan perayaan HUT RI ke70. Survei dan pengabdian masyarakat dengan memberikan pengobatan gratis ini bertujuan untuk mendapatkan data dasar mengenai pola penyakit yang sering diderita sekaligus meringankan beban hidup mereka terutama dalam hal kesehatan dengan cara menerapkan teknik diagnosis dan terapi empirik simptomatik.

\section{METODE}

Kegiatan survei dan pengabdian masyarakat dengan pengobatan gratis ini dilaksanakan di Balai Serba Guna Perumahan Gunung Sari Indah pada Bulan Agustus 2015. Terdapat dua orang dokter, beberapa petugas puskesmas dan puluhan panitia serta kader posyandu Perumahan Gunung Sari Indah yang membantu kegiatan ini. Pada kegiatan ini terdapat sekitar 135 orang kurang mampu yang datang berobat dan berpartisipasi dalam survei. Setiap pasien yang datang dilakukan pencatatan data dasar yang meliputi umur, jenis kelamin, tinggi badan dan berat badan. Anamnesis yang mendalam dengan menggunakan metode empat dasar dan tujuh fundamental dilakukan oleh 2 orang dokter untuk mendapatkan keluhan utama dan keluhan tambahan penderita. Pengukuran tekanan darah dilakukan pada posisi duduk dengan mengadopsi The Canadian Hypertension Guidelines (Daskalopoulou et al., 2015). Pemeriksaan fisik umum yang meliputi tekanan darah, nadi dan suhu tubuh dan pemeriksaan fisik khusus pada sistem organ secara terstruktur juga dilakukan oleh dokter. Pemeriksaan laboratorium tidak dilakukan pada pasien sehingga yang didapatkan hanya diagnosis kerja. Terapi dengan pendekatan empirik diberikan dimana antibiotika hanya untuk pasien yang diduga mengalami infeksi dan pemilihannya berdasarkan kemungkinan sistem organ yang terinfeksi atau pola umum kuman yang menginfeksi. Pendekatan kedua adalah simptomatik dengan pemberian obat untuk mengurangi gejala klinis yang dialami penderita, contohnya analgetik untuk nyeri dan antipiretik untuk demam. 


\section{HASIL DAN PEMBAHASAN}

Survei dan pelayanan kesehatan gratis ini dilakukan di balai serbaguna Perumahan Gunung Sari Indah pada pertengahan Agustus 2015. Pada kegiatan tersebut didapatkan sebanyak 136 orang penderita. Pada gambar 1 terlihat bahwa penderita laki-laki lebih banyak dengan 54\% sedangkan wanita 46\%. Bila dilihat distribusinya menurut umur maka terlihat pada gambar 2 bahwa sebagian besar penderita adalah dewasa berumur $16-59$ tahun $(51,4 \%)$ sedangkan usia balita hanya $6,6 \%$. Terdapat juga 44 orang dengan kategori usia lanjut $(32,3 \%)$ serta $9,5 \%$ penderita usia sekolah 6-15 tahun.

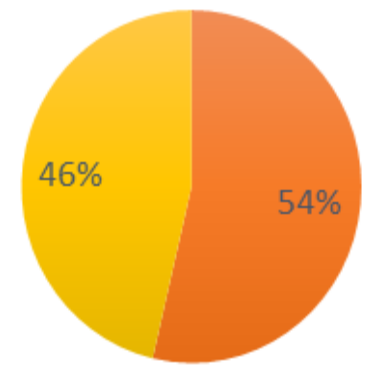

\section{Laki-laki Perempuan}

Gambar 1. Distribusi penderita yang mendapatkan pelayanan kesehatan berdasarkan jenis kelamin

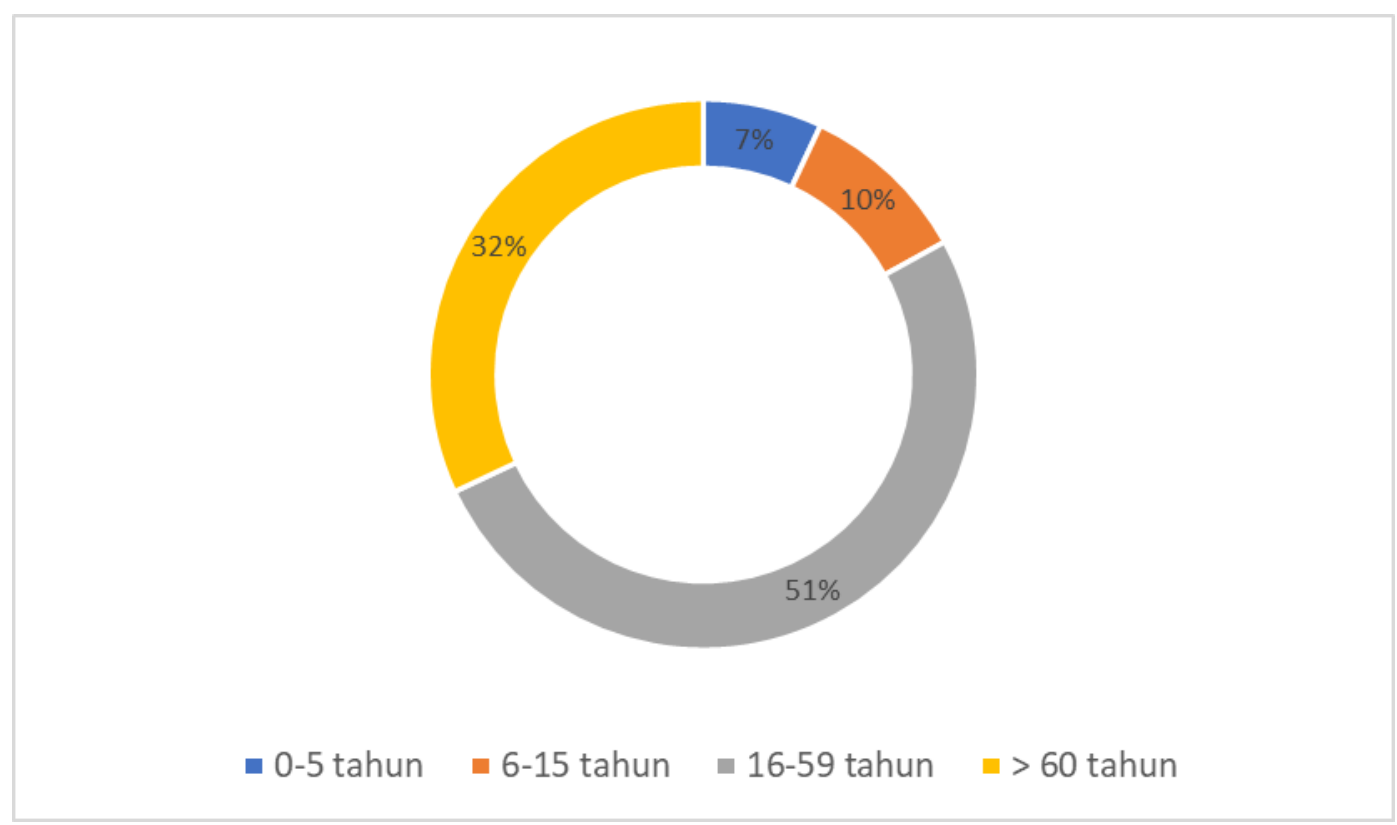

Gambar 2. Distribusi penderita yang mendapatkan pelayanan kesehatan berdasarkan umur

Berdasarkan pola penyakit setempat (gambar 3) didapatkan Infeksi Saluran Pernafasan Atas (ISPA) menempati urutan pertama dengan 30,1\%, diare akut urutan kedua $(19,1 \%)$ dan hipertensi urutan ketiga $(18,3 \%)$. Selanjutnya, 16 orang $(11,7 \%)$ penderita dengan penyakit kulit baik yang disebabkan oleh infeksi bakteri, jamur maupun alergi (eksem) dan 7 orang menderita disentri (5,1\%). Pada grafik 3 tersebut juga terdapat 14 pasien dengan keluhan lain-lain $(10,2 \%)$ seperti dispepsia, tonsilitis, iritasi mata dan otitis eksterna. 


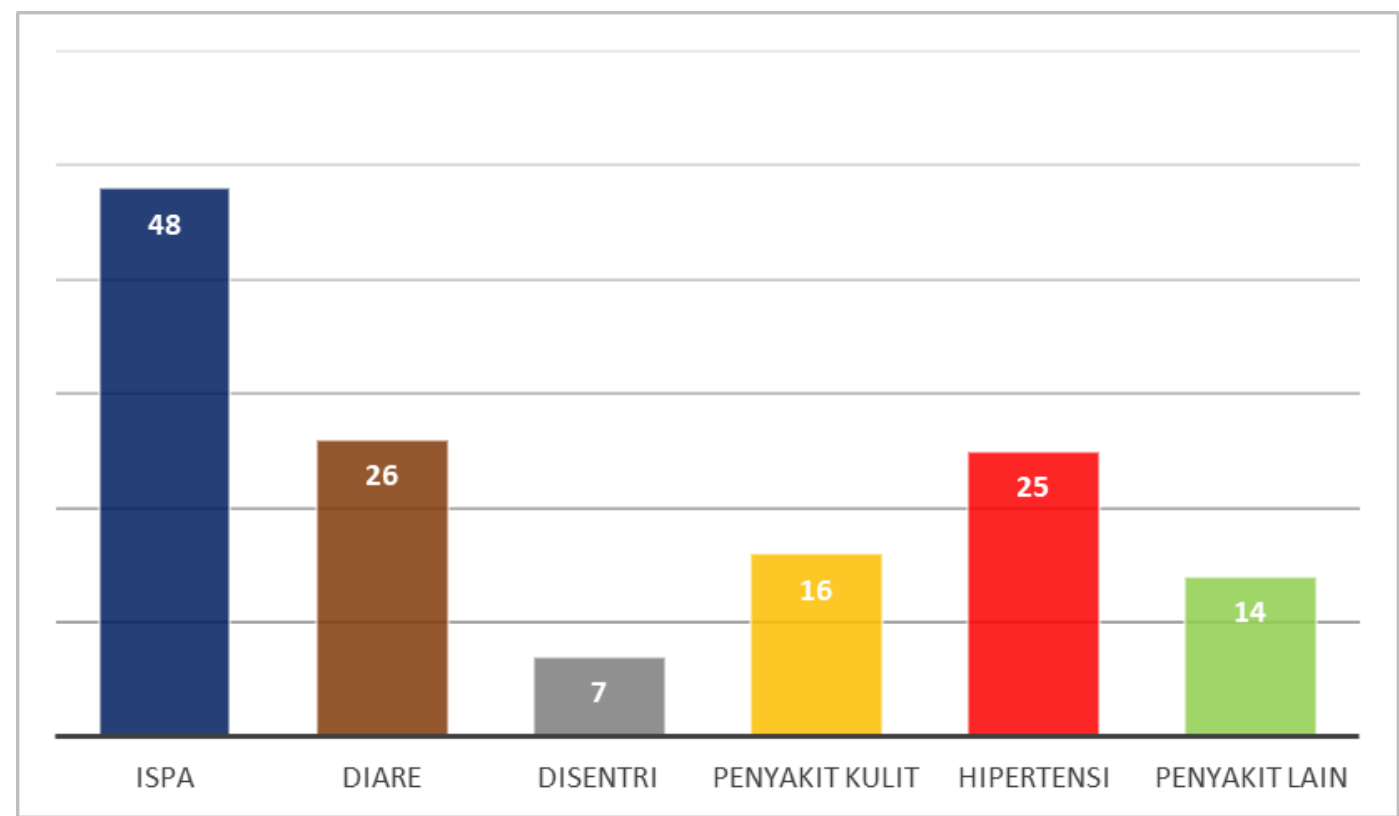

Gambar 3. Distribusi penderita yang mendapatkan pelayanan kesehatan berdasarkan jenis penyakit yang diderita

Berdasarkan jenis terapi yang diberikan (Tabel 1) didapatkan sebanyak 61 penderita mendapatkan antibiotika oral $(44,9 \%)$ dimana jenis antibiotika yang dipilih sangat individual tergantung kondisi dan penyakit pasien. Pendekatan yang digunakan adalah empirik dengan rincian amoksisilin sebanyak 21 orang (34\%), kotrimoksasol 13 orang (21\%), siprofloksasin 10 orang (16\%), eritromisin 4 orang $(7 \%)$, tetrasiklin 8 orang $(13 \%)$ dan metronidasol 5 orang $(8 \%)$. Untuk antibiotika dengan sediaan topikal diresepkan bagi penderita dengan penyakit kulit, mata dan telinga yaitu sebanyak 26 orang $(19,1 \%)$. Obat anti-inflamasi oral seperti deksametason diberikan kepada 42 penderita (30,9\%) sedangkan sediaan bentuk topikal diberikan kepada 16 penderita $(11,8 \%)$. Terapi simptomatik dengan pemberian antidiare dan antipiretik masing-masing diberikan kepada 29 penderita $(21,3 \%)$. Selain itu 22 penderita mendapatkan analgetik $(16,2 \%)$ dan 6 orang mendapatkan obat lambung $(4,4 \%)$.

Tabel 1. Intervensi terapeutik yang diberikan pada pasien di Desa Gunung Sari

\begin{tabular}{lcc}
\hline \multirow{2}{*}{ Intervensi terapeutik } & \multicolumn{2}{c}{ Jumlah pasien yang menerima terapi } \\
\cline { 2 - 3 } & Frekuensi (orang) & Persentase (\%) \\
\hline Antimikroba oral & 61 & 44,9 \\
Antimikroba topikal & 26 & 19,1 \\
Analgetik & 22 & 16,2 \\
Antipiretik & 29 & 21,3 \\
Antidiare & 29 & 21,3 \\
Anti dispepsia & 6 & 4,4 \\
Anti inflamasi oral & 42 & 30,9 \\
Anti inflamasi topikal & 16 & 11,8 \\
Anti hipertensi & 25 & 18,4 \\
\hline
\end{tabular}

Sebanyak 136 penderita datang ke tempat pelayanan kesehatan gratis sekaligus sebagai sampel dalam survei pola penyakit yang ada di wilayah Desa Gunung Sari, Lombok Barat. Distribusi penderita berdasarkan jenis kelamin menunjukan proporsi laki-laki lebih banyak dengan 53,7\%, dimana hasil ini berbeda dengan temuan studi di Finlandia (Hirsikangas et al., 2016). 
Distribusi penderita menurut umur memperlihatkan adanya dominasi penderita dewasa (16-59 tahun) dan lansia yaitu masing-masing 51,4\% dan 32,3\%. Temuan ini sedikit berbeda dari survei yang dilakukan di Karawang dimana penderita usia lanjut mendominasi kunjungan ke pusat pelayanan primer (Abdulah et al., 2019). Hal ini mungkin disebabkan karena di Indonesia telah ada program posyandu yang mewajibkan setiap balita dan anak-anak untuk datang rutin kontrol maupun berobat sehingga mereka tidak memiliki permasalahan kesehatan yang berarti dan tidak datang lagi ke pelayanan kesehatan gratis (Nugraheni and Hartono, 2017). Kualitas pelayanan kesehatan gratis dirasakan masih kurang oleh orang tua, bisa merupakan sebab lain tidak banyak pasien anak dan remaja yang datang berkunjung (Kamiroki et al., 2018).

Berdasarkan pola penyakit terutama pada warga miskin di Desa Gunung Sari, ISPA dan diare merupakan dua urutan teratas dengan $30,1 \%$ dan $19,1 \%$. Pola penyakit ini sesuai dengan laporan rutin Puskesmas Gunung Sari dan profil kesehatan Kabupaten Lombok Barat yang menempatkan ISPA, diare dan penyakit kulit sebagai 3 penyakit dengan kunjungan tersering (Dinas Kesehatan Lombok Barat, 2013). Temuan ini juga mirip dengan pelayanan kesehatan gratis yang dilakukan di Nepal (Thapa et al., 2015).

Berpatokan pada pola penyakit, pola infeksi kuman dan kemungkinan penyebab kelainan organ maka terapi yang diberikan berdasarkan metode empirik untuk antibiotika. Antimikroba oral diberikan kepada 44,9\% penderita, dimana jenis amoksisilin yang terbanyak yaitu 21 orang (34\%) dan metronidasol yang paling sedikit yaitu 5 orang $(8 \%)$. Antibiotika oral terutama diberikan pada penderita ISPA, diare, disentri, penyakit kulit maupun infeksi lain yang mengalami demam dan diduga penyebabnya bakteri. Amoksisilin terutama diindikasikan untuk ISPA, siprofloksasin untuk infeksi saluran kemih dan metronidasol untuk disentri yang disebabkan oleh amoeba (Abdulah et al., 2019; Nugraha and Inayah, 2017). Sebagai tambahan juga diberikan antiinflamasi baik oral maupun topikal khusus untuk kasus-kasus yang terbukti mengalami peradangan seperti ISPA akibat tonsilitis atau faringitis akut, demam akibat abses kulit dan otitis media akut yang relatif berat (Thapa et al., 2015).

Terapi dengan pendekatan simptomatik berupa antipiretik diberikan kepada 29 orang $(21,3 \%)$, analgetik untuk 22 orang $(16,2 \%)$ dan antidiare untuk 29 orang (21,3\%). Terapi ini berguna untuk mengurangi gejala penyakit seperti demam, nyeri perut, sakit kepala, nyeri sendi dan mencret. Selain dapat memberikan rasa nyaman yang sifatnya segera terapi simptomatik juga dapat mempercepat proses penyembuhan (Neyaz et al., 2011).

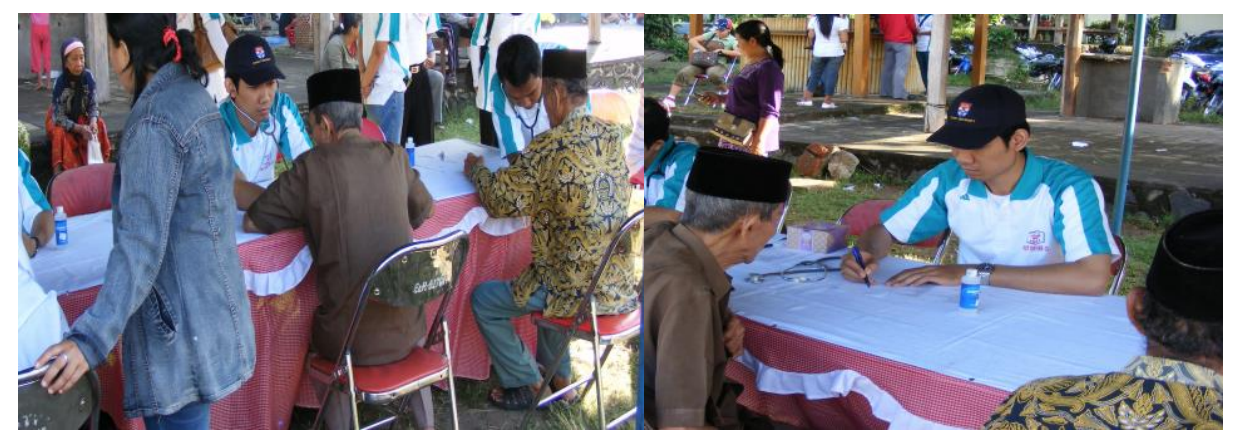

Gambar 4. Dokumentasi pelaksanaan pelayanan kesehatan gratis. 


\section{KESIMPULAN DAN SARAN}

Pola penyakit pada masyarakat miskin di Desa Gunung Sari sesuai dengan yang ditemukan di daerah lain di Kabupaten Lombok Barat yaitu ISPA, diare dan penyakit kulit yang memang sangat berkaitan dengan pola hidup bersih yang kurang, lingkungan yang kotor dan akses air bersih yang kurang memadai. Pemberian pengobatan gratis dengan pendekatan empirik dan simptomatik sangat membantu mengurangi beban fisik maupun psikologis penderita sehingga mereka dapat kembali bekerja untuk memenuhi kebutuhannya. Aplikasi klinis metode terapi empirik simptomatik ini sangat tepat untuk digunakan karena sifatnya yang praktis dan ekonomis. Walaupun demikian, perlu diingat bahwa dalam kesehatan masyarakat prinsip pencegahan tetap lebih baik dari pada pengobatan.

\section{Ucapan Terima Kasih}

Penulis mengucapkan terimakasih sebesar-besarnya kepada Panitia HUT RI-70 Perumahan Gunung Sari Indah, seluruh staf Puskesmas Gunung Sari dan Masyarakat setempat yang membantu terlaksananya kegiatan Pengabdian Kepada Masyarakat survei dan pengobatan gratis tersebut.

\section{DAFTAR PUSTAKA}

Abdulah, R., Insani, W.N., Destiani, D.P., Rohmaniasari, N., Mohenathas, N.D., Barliana, M.I. 2018. Polypharmacy leads to increased prevalence of potentially inappropriate medication in the Indonesian geriatric population visiting primary care facilities. Therapeutics and Clinical Risk Management. 14: 1591-1597.

Abdulah, R., Insani, W.N., Putri, N.E., Purba, H.P., Destiani, D.P., Barliana, M.I. 2019. Pattern of medication use in geriatric patients at primary health care facilities in karawang, Indonesia. Drug Healthcare and Patient Safety. 11: 1-5.

Daskalopoulou, S.S., Rabi, D.M., Zarnke, K.B., Dasgupta, K., Nerenberg, K., Cloutier, L., Gelfer, M., Lamarre-Cliche, M., Milot, A., Bolli, P., McKay, D.W., Tremblay, G., McLean, D., Tobe, S.W., Ruzicka, M., Burns, K.D., Vallée, M., Ramesh Prasad, G. V., Lebel, M., Feldman, R.D., Selby, P., Pipe, A., Schiffrin, E.L., McFarlane, P.A., Oh, P., Hegele, R.A., Khara, M., Wilson, T.W., Brian Penner, S., Burgess, E., Herman, R.J., Bacon, S.L., Rabkin, S.W., Gilbert, R.E., Campbell, T.S., Grover, S., Honos, G., Lindsay, P., Hill, M.D., Coutts, S.B., Gubitz, G., Campbell, N.R.C., Moe, G.W., Howlett, J.G., Boulanger, J.M., Prebtani, A., Larochelle, P., Leiter, L.A., Jones, C., Ogilvie, R.I., Woo, V., Kaczorowski, J., Trudeau, L., Petrella, R.J., Hiremath, S., Stone, J.A., Drouin, D., Lavoie, K.L., Hamet, P., Fodor, G., Grégoire, J.C., Fournier, A., Lewanczuk, R., Dresser, G.K., Sharma, M., Reid, D., Benoit, G., Feber, J., Harris, K.C., Poirier, L., Padwal, R.S. 2015. The 2015 Canadian Hypertension Education Program Recommendations for Blood Pressure Measurement, Diagnosis, Assessment of Risk, Prevention, and Treatment of Hypertension. Canadian Journal of Cardiology. 31: 549-568.

Dinas Kesehatan Lombok Barat. 2013. Profil Kabupaten Lombok Barat Tahun 2013. Dinkes Lombok Barat. Gerung.

Hirsikangas, S., Kanste, O., Korpelainen, J., Kyngäs, H. 2016. Adherence to health regimens among frequent attenders of finnish healthcare. International Journal of Circumpolar Health. 75: 1-8.

Jiwantoro, Y.A. 2019. Optimalisasi "Bu.Pur" Sebagai Upaya Pencegahan Dan Pengobatan Penyakit Degeneratif Pada Lansia Di Dusun Karang Bayan Barat Desa Karang Bayan Kecamatan Lingsar Lombok Barat. Jurnal Pengabdian Masyarakat Sasambo. 1: 1-5. 
Kamiroki, E.Y., Rorong, A.J., Ruru, J.M. 2018. Kualitas Pelayanan Kesehatan Gratis Di Rumah Sakit Umum Kabupaten Nabire Papua. Jurnal Administrasi Publik. 4: 1-4.

Neyaz, Y., Khoja, T., Qureshi, N.A., Magzoub, M.A., Haycox, A., Walley, T. 2011. Predictors of quality of medication prescribing in primary care in Riyadh city, Saudi Arabia. The Eastern Mediterranean Health Journal. 17: 167-171.

Nugraha, D.P., Inayah, I. 2017. Gambaran Farmakoterapi Pasien Common Cold Di Puskesmas Pekanbaru. Jurnal Ilmu Kedokteran. 10: 63-66.

Nugraheni, W.P., Hartono, R.K. 2017. Analisis Pola Layanan Kesehatan Rawat Jalan pada Tahun Pertama Implementasi Program Jaminan Kesehatan Nasional (JKN). Media Penelitian dan Pengembangan Kesehatan. 27: 9-16.

Prasetio, E., Utami, W., Othman, Z., Wardani, A., Rahem, A., Hermansyah, A. 2020. Evaluation of rational drug use based on World Health Organization prescribing indicators in a primary care center in Pamekasan East Java, Indonesia. Journal of Basic Clinical Physiology and Pharmacology. 1: 1-8.

Riskesdas NTB. 2018. Laporan Provinsi Nusa Tenggara Barat Riskesdas 2018. Lembaga Penerbit Badan Penelitian dan Pengembangan Kesehatan. Jakarta.

Santos-Guzman, J., Gonzalez-Salazar, F., Martínez-Ozuna, G., Jimenez, V., Luviano, A., Palazuelos, D., Fernandez-Flores, R.I., Manzano-Camarillo, M., Picazzo-Palencia, E., Gasca-Sanchez, F., Mejia-Velazquez, G.M. 2021. Epidemiologic impacts in acute infectious disease associated with catastrophic climate events related to global warming in the northeast of Mexico. International Journal of Environmental Research and Public Health. 18: 1-13.

Thapa, R.K., Thapa, P., Parajuli-Baral, K., Khan, G.M. 2015. Disease proportions and drug prescribing pattern observed in a free health camp organized at Dhorphirdi Village Development Committee of Western Nepal. BMC Research Notes. 8: 4-9.

Watkins, J.B. 2018. Affordability of Health Care: A Global Crisis. Value Health. 21: 280-282. 